\title{
Cuento ilustrado. Cuatro aproximaciones a través de tres revistas literarias colombianas ${ }^{1}$
}

\author{
Diana Carolina Toro Henao ${ }^{2}$
}

Resumen. Este artículo analiza los cuentos ilustrados publicados en las revistas literarias colombianas Lectura y arte (1903), La Niñez (1914) y Rin-rin (1936). En primer lugar, se analizan las publicaciones de cuentos que se ilustran con una imagen, se reflexiona acerca de la relación que se establece entre ambos objetos; a continuación, se estudian los textos que se acompañan de varias ilustraciones que conforman una secuencia narrativa, a partir de la disposición de varias imágenes. Luego, se presenta el análisis de los cuentos mudos, una serie de dibujos que carecen de texto escrito. Finalmente, se abordan historietas, donde se disponen unas imágenes acompañadas de textos cortos. Palabras clave: publicaciones periódicas; siglo XX; prensa ilustrada; cuento.

\section{[en] Illustrated story. Four definitions through three literary Colombian magazines}

\begin{abstract}
This article analizes the illustrated stories published in the literary Colombian magazines Lectura y arte (1903), La Niñez (1914) and Rin-rin (1936). In first place, it has been analyzed the publications of stories that are illustrated with one image, we reflected about the relationship that is stablished between both objects; then, it has been studied the texts that are accompanied with several illustrations that define a narrative sequence, from the disposition of different images. After, it's been presented the analysis of the mute stories, one series of draws that lack of written text. Finally, it's been broached cartoon strips, where it's been disposed some images shared with short texts.
\end{abstract}

Keywords: Periodicals; Twentieth Century; Illustrated Press; Fairy Tale.

Sumario. 1. Introducción. 2. ¿Un texto o dos? 3. Secuencia narrativa. 4. Cuento mudo. 5. Historias historiadas. 6. A modo de conclusión.

Cómo citar: Toro Henao, D.C. (2018) Cuento ilustrado. Cuatro aproximaciones a través de tres revistas literarias colombianas, en Anales de Literatura Hispanoamericana 47, 91-108.

1 Artículo derivado de la investigación "El cuento colombiano en las revistas literarias colombianas (19001950). Estudio histórico y hemerográfico”, asimismo se inscribe en la Estrategia de Sostenibilidad para grupos de investigación Universidad de Antioquia, UdeA, 2016-2017.

2 Universidad de Antioquia, Medellín. Colombia.

E-mail: carotora@hotmail.com 


\section{Introducción}

Este trabajo busca presentar el análisis de los cuentos ilustrados publicados en tres revistas literarias colombianas: Lectura y arte (1903), La Niñez (1914) y Rin-rin (1936), a partir de las relaciones entre imágenes y textos configuradas en ellos. Se centra en los productos literarios, entendidos en estas circunstancias como los textos escritos y las imágenes publicadas en las revistas Lectura y Arte, La Niñez y Rin-rin; sin desconocer las conexiones e intersecciones con los demás elementos del sistema literario.

La presente investigación se inscribe en el proyecto "El cuento en revistas literarias colombianas (1900-1951). Aportes a una historia del género”, los textos ilustrados seleccionados para el análisis se reconocen como narrativos, más específicamente como cuentos, aunque no todos son designados de tal forma por las revistas. Las publicaciones periódicas escogidas (Lectura y Arte La Niñez y Rin-rin) hacen parte del corpus principal del proyecto, el cual abarca revistas publicadas entre 1900 y 1951. Los criterios de selección se centraron en la inclusión de imágenes que acompañaran cuentos o que ellas mismas se constituyeran en textos narrativos, se eligieron tres revistas relevantes que contaran con una distancia entre los tiempos de publicación para observar de manera general tres momentos del fenómeno literario en el periodo delimitado por el proyecto de investigación.

El nacimiento de la prensa ilustrada, no solo la literaria, fue un fenómeno extendido; comenzó en Europa en Inglaterra y Francia, luego tuvo lugar en España y finalmente llegó a América Latina (Reyes 1988). El surgimiento de la prensa literaria ilustrada en Colombia se señala en el comienzo de la publicación de $E l$ Neogranadino en 1849, iniciativa del notable escritor Manuel Ancízar, lograda en colaboración de los litógrafos Jerónimo y Celestino Martínez; quienes sobresalen por haber sido pioneros en la utilización del grabado como medio de divulgación en la prensa (Giraldo, 1980). Si bien en los países europeos hay un corpus significativo del estudio de la imagen en las publicaciones periódicas, resulta interesante descubrir que este tema ha sido poco abordado en Colombia, de ahí que se requiera emprender distintos estudios de la imagen en la prensa y en particular de las relaciones entre textos e imágenes en la prensa ilustrada.

Las ilustraciones de las revistas literarias del país cobran fuerza de manera contundente a partir de la publicación del Papel Periódico Ilustrado, publicado durante los años 1881-1888 en 116 números y cinco volúmenes y dirigido por Alberto Urdaneta. El Papel Periódico Ilustrado se destaca por ser unas de las publicaciones periódicas ilustradas de mayor relevancia en el país, no solo por su permanencia y la cantidad de textos publicados, sino por lo que significó para el proceso de modernización del arte en Colombia y por ser una especie de archivo de la ciencia, el arte y la literatura a finales del siglo XIX. Se relaciona con proyectos como Los españoles pintados por sí mismos (1843-1844) y Los Mexicanos pintados por sí mismos (1866), en los cuales los textos literarios e imágenes se trazaban un objetivo común de presentar aquellas características de los tipos, lugares y costumbres de la nación.

Se esbozan como marco conceptual del presente estudio los postulados teóricos de Itamar Even Zohar (1990) acerca del sistema literario y la teoría de los 
polisistemas, bajo la cual se comprende la literatura como un fenómeno semiótico, razón por la cual se considera más pertinente entenderla y estudiarla como un sistema, un sistema que interactúa y se relaciona con otros sistemas y que, a su vez, se estructura a partir de las relaciones entre los elementos que lo configuran; a saber $^{3}$ : productor (emisor), producto (mensaje), consumidor (receptor), repertorio (código), institución (contexto) y mercado (canal); cada elemento asume unas funciones particulares que se intersectan con las demás. No obstante, es necesario aclarar que este trabajo se concentra en los productos literarios, es decir, los textos escritos y las imágenes publicadas.

Las relaciones entre el lenguaje y el arte, más específicamente entre la palabra y la imagen, han sido objeto de reflexión y discusión a través de la historia del pensamiento desde la Grecia Antigua. Wladislaw Tatarkiewicz (2010), por ejemplo, refiere los planteamientos del griego Dío, llamado Crisóstomos, quien postula cuatro diferencias entre ambos campos de la estética. Leonardo Da Vinci discurre también alrededor de la distinción entre estos objetos, destacando la particularidad de la pintura, y más adelante, Gotthold Lessing, en el siglo XVIII, delibera en torno a la tensión entre palabra e imagen a raíz de la obra escultórica y el relato sobre Laocoonte, resalta las distinciones y separa sus alcances y funciones.

A partir del giro lingüístico ya entrado el siglo $\mathrm{XX}$, se ampliaron las perspectivas de análisis acerca de las conexiones entre estos dos objetos y varios estudiosos realizaron propuestas que se alejaban del estudio comparativo entre palabra e imagen e indagaban más bien por la relación en sí y las construcciones que se derivaban de ella; es el caso de planteamientos como los de Aron Kibédi Varga, Michael Rifaterre y Vicenç Furió. En esta perspectiva se plantea este trabajo de análisis, es decir, en la línea de comprender el enlace entre palabra e imagen que se configura en las publicaciones periódicas utilizadas como fuente.

Es relevante esclarecer que en la labor investigativa llevada a cabo se toma como referencia el concepto de imagen especificado por Ana García Varas (2011), quien concibe que el significado de la imagen no se reduce a lo referencial ni está dispuesto como algo exclusivo y único, sino que se construye a partir de las cualidades de la misma, mediante las cuales se transforma la materia en sentido. En esta línea, se utiliza la teoría de la percepción visual de Rudolph Arnheim con el propósito de entender la imagen desde la configuración de su significado a través de las características que la estructuran.

El concepto de ilustración se aprecia a partir de las reflexiones acerca del costumbrismo y la prensa ilustrada de los investigadores españoles Ignacio GilDíez (2004) y Borja Rodríguez Gutiérrez (2011). Estos autores esbozan una particular conexión entre imagen y texto que reconocen como ilustración y que se caracteriza por acompañar al texto escrito, por complementarlo, por ligarse a él de un modo especial, en tanto que la imagen se dispone a presentar lo referido por la palabra, para aportar información o reforzar un contenido. Debe esclarecerse, igualmente, que la noción de texto no se reduce al aspecto lingüístico, sino que se advierte como una construcción semiótica, de signos verbales o visuales; por tanto,

Itamar Even Zohar toma como base el esquema de la comunicación propuesto por Roman Jakobson para configurar los elementos del sistema literario. 
las referencias al texto dentro del artículo aluden tanto al escrito como al visual o gráfico.

Lectura y arte se publica en Medellín entre 1903 y 1906 bajo la dirección de Antonio J. Cano, Enrique Vidal, Francisco A. Cano y Marco Tobón Mejía, este último colaboró como ilustrador de los artículos en varios de los números. En el prospecto se señala que a pesar de las dificultades de publicación sale a la luz el primer número y se disponen a entregar un número mensual. Se define como una publicación periódica con una finalidad artística y literaria, pues buscan contribuir en el "cultivo del espíritu" en el país. Se revela que publicarán también producciones de interés patrio y universal. Aseguran no pertenecer a ninguna escuela y que incluirán cosas en contra de su ideología. Por su parte, La Niñez surge en la ciudad de Bogotá en enero de 1914, dirigida por Martín Restrepo Mejía, tiene un carácter pedagógico infantil, desde el prospecto se esclarece que sus contenidos están escritos y publicados para los “chiquitines". Se menciona que se insertarán artículos geográficos, históricos, cuentos, poemas, acertijos y problemas y además se ha solicitado la ilustración de "hermosos grabados". El propósito es ofrecerles a los infantes "un vaso de vino de la verdad y un ramillete de flores" (Restrepo, 1914: 1). Mientras tanto, Rin-rin es la revista infantil del Ministerio de Educación, se publica a partir de 1935 en Bogotá "para todos los niños de Colombia”; se les invita a escribir acerca de lo que desean leer y a enviar sus creaciones, que bien pueden ser prosa, verso, dibujo, caricatura. Asimismo, se cuenta en el prospecto que se ha solicitado la colaboración de hombres de méritos reconocidos para asegurar "un buen material de lectura” y el disfrute de los niños.

De las relaciones entre imágenes y textos observados en las tres revistas analizadas es posible elaborar una clasificación a partir de la manera en que ambos elementos se configuran. En primer lugar, puede apreciarse un texto narrativo que se acompaña de una única imagen; luego, se halla un relato escrito asociado con una serie de ilustraciones (entre tres y diez). A continuación, la revista La Niñez expone dos interesantes productos: el "cuento mudo", que se caracteriza precisamente por carecer de palabras y un tipo de "historieta", en la cual las imágenes se enlazan con unos cortos textos escritos.

\section{2. ¿Un texto o dos?}

En el número 11 (1905) de la revista Lectura y Arte se publica "Risa trágica”, una construcción verbal y visual donde ambos objetos se ven complementados. Se observa una imagen (imagen 1) que sirve de marco para el texto escrito al mismo tiempo que expresa una interpretación del mismo a partir de características gráficas. La fuerza trágica que se manifiesta desde el título se evidencia en la composición textual y se enfatiza en la configuración de imágenes. 


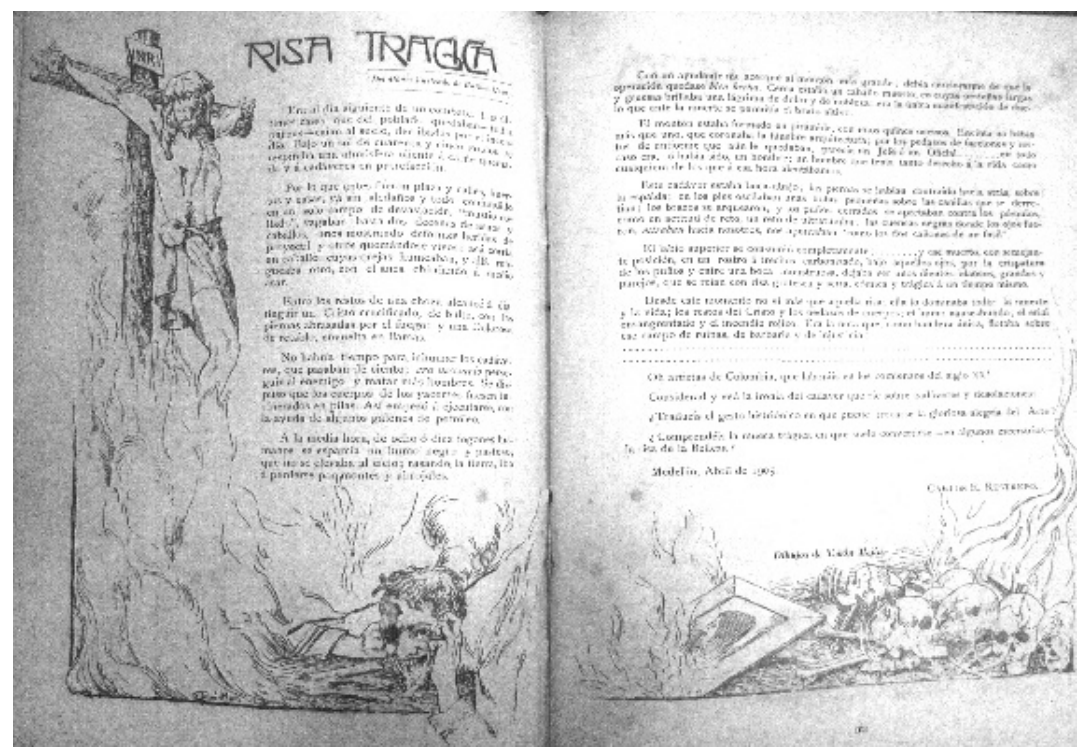

Img. 1. “Risa trágica”, Lectura y Arte, nº 11, 1905, p. 202

Esta última interesa, además, por conectar en una misma unidad gráfica, varias escenas del relato. Así, por ejemplo, se incluyen dentro de un mismo escenario visual:

a. Crucifijo: "Entre los restos de una choza alcancé a distinguir un Cristo crucificado, de bulto, con las piernas abrasadas por el fuego; y una Dolorosa de retablo, envuelta en llamas" (Restrepo 1905: 202). El dibujo revela las piezas abrasadas por el fuego; sin embargo, Marco Tobón Mejía, el ilustrador, se toma la libertad de no disponer el crucifijo ubicado entre los despojos de una choza, sino que lo sitúa en el lado izquierdo, otorgando una relevancia mayor a este objeto y a lo que simboliza: la moral cristiana y el valor del amor al prójimo que se contrapone a los desastres de la guerra. Llama la atención que, a diferencia del crucifijo, la Dolorosa de retablo esté en el suelo, cubriéndose de brasas, aunque no es muy clara la imagen de la virgen María; esto incide en la importancia que quiso otorgarse a este símbolo en otra dirección a la de la escena exhibida.

b. Hombre con la mueca en el rostro: "El labio superior se consumió completamente... y ese muerto, con semejante posición, en un rostro a trechos carbonizado, bajo aquellos ojos, por la crispatura de los puños y entre una boca monstruosa, dejaba ver unos dientes blancos, grandes y parejos, que se reían con risa grotesca y seria, cómica y trágica a un tiempo mismo.” (Restrepo 1905: 203). Tobón Mejía sigue de cerca la descripción: los puños, las cuencas, el labio y las llamas.

c. Cadáveres: "se respiraba una atmósfera oliente a carne quemada y a cadáveres en putrefacción” (Restrepo 1905: 202). En la ilustración, sobre la derecha, se disponen unos cráneos y algunos huesos entre el fuego. 
La ilustración, por tanto, es una composición a partir de una lectura completa del relato, donde se configura, pero de forma gráfica, la principal denuncia que realiza Carlos E. Restrepo: "Considerad y ved la ironía del cadáver que ríe sobre cadáveres y desolaciones” (1905: 203). Ambos objetos evidencian los desastres de la guerra y oponen la vida frente a la muerte, a través del personaje que narra u observa la escena. El ilustrador dibuja la escena vista por el narrador, nos revela lo que sus ojos vieron, y lo hace mezclando momentos diversos de la misma situación.

Por otra parte, en el relato "Una batalla china”, escrito por el niño Álvaro Molano de 14 años y divulgado en el número 3 de Rin-rin (1936) en la sección “Colaboración infantil”, se propone otra conexión entre los elementos puesto que es el mismo escritor quien ilustra su texto (imagen 2). Debe resaltarse el hecho de que el editor de la revista se preocupe por publicar ambos elementos y disponga el espacio para hacerlo. En este caso, la imagen se estructura como una ilustración de un instante en especial de la narración "El astrónomo [...] en contestación tomó su anteojo de larga vista y examinando detenidamente la superficie del mar exclamó ‘Truenos y ravioles! ¡Una isla!” (Molano 1936: 15).

El foco de la ilustración lo ocupa justamente la isla, la cual es, asimismo, el punto central del cuento. Las peripecias se desarrollan a raíz de esta isla, sobre la que descubren que no es más que el reflejo ante el espejo del propio reiN ${ }^{\circ}$ Es importante anotar, entonces, que la coincidencia entre imagen y texto parte de la misma persona, quien crea un objeto compuesto de dos elementos: texto verbal e ilustración.

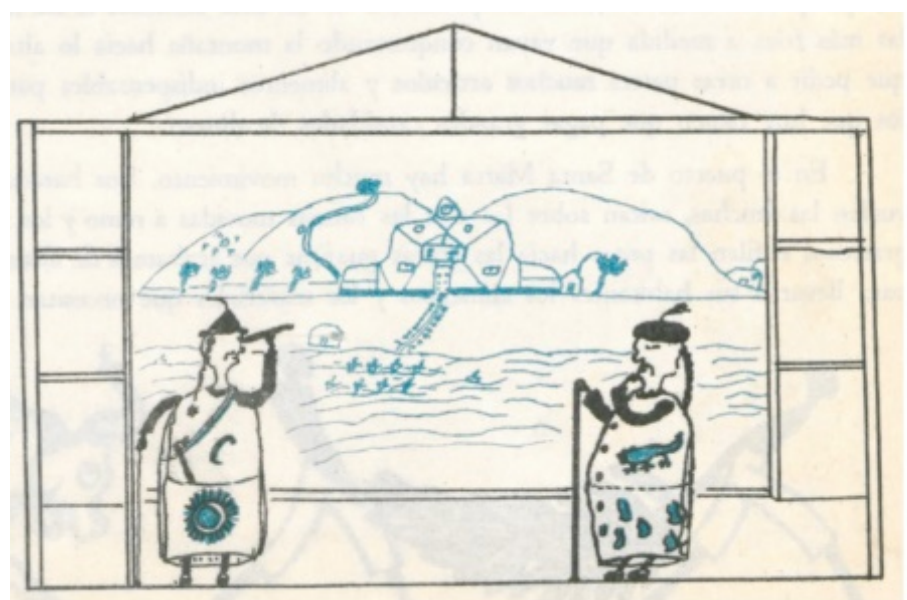

Img. 2. “Una batalla china”, Rin-rin, nº 3, 1936, p. 15.

Ahora, también en Rin-rin se publica en el número 6 (1936) la fábula de "La pobre viejecita” de Rafael Pombo. Allí se incluye una gran ilustración (imagen 3) que entra en relación con el texto, e incluso visualmente lo opaca. Está constituido por una gran escena dividida en dos partes; sin embargo, se enlazan. En el lado izquierdo, bajo las primeras estrofas se ubica el personaje de la viejecita sentada mirando hacia el lector en un sofá con banquitos y cojines y resorte al espaldar, rodeada de ocho gatos y un turpial, mientras observa a su izquierda que vienen 
hacia ella las ocho criadas, los dos pajes y Andrés, Juan y Gil con cacerolas y platos. De esta manera, se percibe que la ilustración expresa una composición, más que de escenas de la fábula, de la descripción del personaje; allí confluyen la comida, la compañía, los muebles y las mascotas. Se aporta información al texto: el vestuario de los criados y de la viejecita, los cuerpos y rostros de los personajes y las mascotas.

En la ilustración se advierten algunas tensiones que dan cuenta del movimiento en esa imagen estática; por ejemplo, la tensión entre la mirada de la viejecita y el cortejo o entre los hombres que dan la espalda y quienes están caminando. Las diagonales de los cuerpos y el humo que sale de platos y cacerolas refuerzan esa moción. Es relevante destacar este aspecto en la medida en que se revela una dimensión narrativa en la imagen, otorgada por la configuración de la misma, lo cual permite afirmar que en publicaciones como "La pobre viejecita" se configuran dos relatos: uno verbal y otro visual; y estos se relacionan de manera complementaria, aunque en este caso, es clara la preponderancia de la fábula escrita por Pombo, pues el dibujo se supedita a ella.

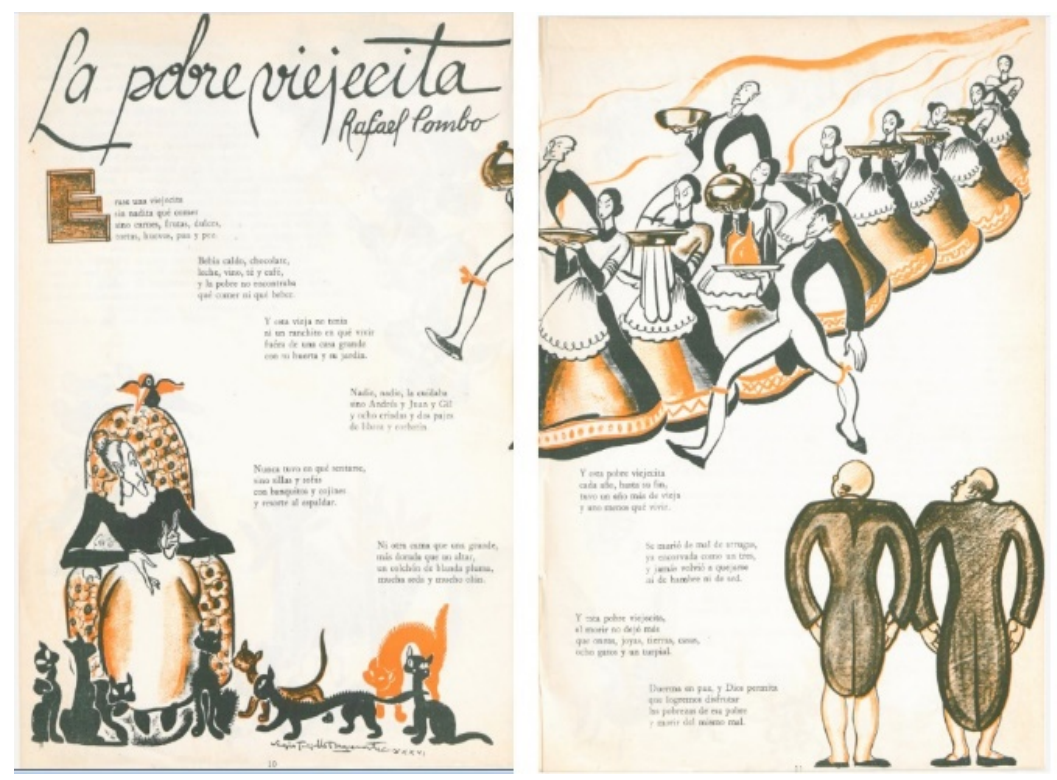

Img. 3. "La pobre viejecita”, Rin-rin, no. 6, 1936, p. 10-11

Con base en estos tres ejemplos seleccionados, se aprecia, pues, que hay dos relaciones en los textos narrativos que se acompañan de una única ilustración; primero, se insertan textos que se configuran como una unidad creada por un relato escrito y una imagen compuesta, sujeta a este; y segundo, se introducen dos textos: uno verbal y otro visual que actúan como relatos que se complementan, pero en los cuales se puede observar cierta independencia entre las dimensiones temporales que estructuran. A partir de esta conclusión, puede aseverarse que ambos tipos de textos son cuentos ilustrados, en la medida en que son relatos escritos a los cuales 
se les inserta como elemento adicional una única ilustración que refuerza el contenido de los textos verbales, amplía la descripción de los personajes y los espacios o estructuran un relato "paralelo" desde aspectos gráficos.

\section{Secuencia narrativa}
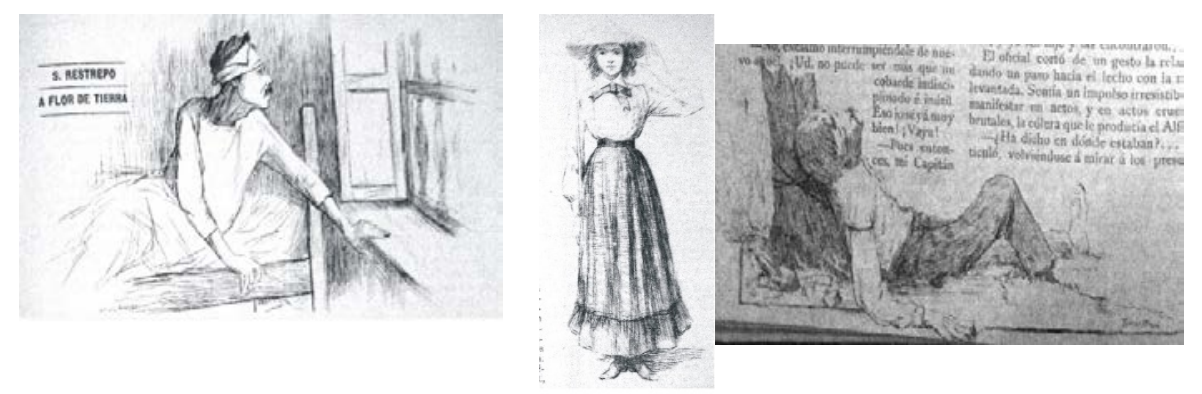

Img. 4. “A flor de tierra”, Lectura y arte, nº 7 y 8, 1904, p. 129, 133, 140.

"A flor de tierra" es un extenso cuento de S. Restrepo publicado en Lectura y arte (1904), al cual se le incluyeron tres grabados a lo largo de la disposición del mismo. El primero de ellos (imagen 4) se ubica al principio del texto escrito; aunque la escena es mencionada en la página siguiente, se percibe en ella la fuerte tensión entre el exterior y el interior, tanto como para hacer que el individuo se siente en la cama, en vez de permanecer descansando como parece que debe hacerlo dado su aspecto enfermizo. Se muestra una interrupción de la calma y la serenidad del cuarto, interrupción que se manifiesta en la concentración de la mirada y la rigidez del cuerpo y el cuello. Esa tensión es resuelta por la narración, en donde se expone la causa de la perturbación: "Manolo se irguió un poco y miró allá. Vio un grupo de soldados [...] Manuel volvió a otra parte los ojos, estremeciéndose” (Restrepo 1904: 130). A pesar de que en la ilustración no se evidencia el cuadro que hizo estremecer a Manuel, se advierte la trascendencia de este por la tensión que se expresa en el personaje que observa con detenimiento. Es notable mencionar que el hombre dibujado por Tobón Mejía se distancia de la fisonomía revelada en la escritura; allí Manuel mismo se describe "débil de músculos, aunque gordo” (Restrepo 1904: 130). El ilustrador se toma la libertad de crear un soldado con otras facciones, por lo menos en cuanto a que no se muestra su "gordura".

La siguiente ilustración actúa como un retrato del personaje femenino de la historia, se configura una mujer con facciones serias, en posición militar, muy rígida. Tiene un sombrero y un palo en la mano En el cuento se expresa que "Ella los saludó militarmente con su gracia habitual y burlona de pájaro travieso y siguió en marcha" (Restrepo 1904: 132). No obstante, no se descubre ese carácter travieso y burlón de la joven en la imagen. Tampoco es claro por qué lleva un palo; en el relato se habla de una espada que toma sin permiso del soldado postrado; aunque al tiempo que se apropia de este objeto, también lo hace de un cartucho, y este no se 
ve en la ilustración. Esto se puede contemplar como otro detalle que es incluido por el ilustrador, en su papel de creador y configurador de las imágenes, las cuales, si bien se relacionan con el texto, no lo repiten.

Finalmente, la secuencia termina con el cuadro que concluye el relato, revelando la suerte del soldado. La ilustración muestra un hombre atado a un tronco con la cabeza caída hacia atrás, no logra sostenerse; motivo por el cual parece declararse que ha fallecido. La cabeza presenta una deformidad, como la mano que rasguña la tierra, en un gesto brusco. El centro de la imagen se halla justamente en la cabeza del hombre, enfatizando lo que el mismo cuento enuncia que "Manuel había callado", se doblega inerte entre los brazos de los soldados mientras lo atan. El grabado resuelve algo que el texto no narra de manera directa: a Manuel lo habían alcanzado a amarrar, a pesar de estar muerto. El cuerpo ilustrado da cuenta aun de la oposición entre vida y muerte, en tanto que su cabeza cae, pero su rodilla aún se mantiene doblada.

Estas tres imágenes forman una serie que muestra la selección del ilustrador acerca de momentos claves del relato, el inicio cuando se muestra el personaje principal y la dicotomía que enfrenta por ser un soldado que debe permanecer en el hospital mientras afuera se mueven otras fuerzas que lo llaman; luego, la mujer, quien obra un papel importante en la suerte de Manuel al tomar sus objetos y es a causa de este hecho que lo arrastran al final y que van a atarlo para fusilarlo, por órdenes del capitán, y por último, la muerte impredecible del personaje. Las ilustraciones si bien recrean tres escenas del cuento, le añaden información que este no ofrecía, lo cual les otorga a estas ilustraciones un rol creador, configurador de escenas más que mimético.
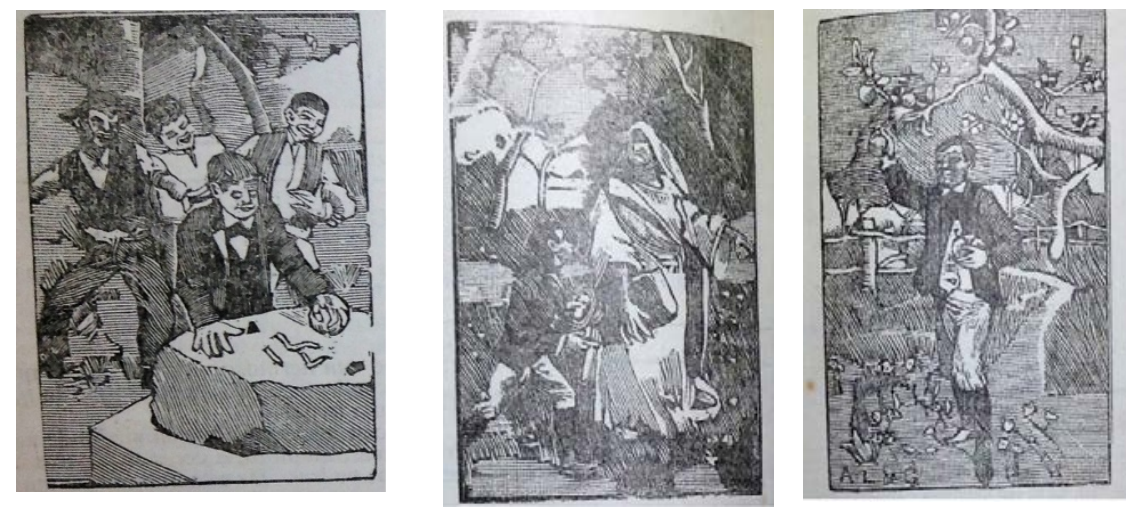

Img. 5. “Las botas de cien leguas”, La Niñez, nº. 11, 1914, p. 262, 263.

La Niñez publica en el $\mathrm{n}^{\circ}$. 11 (1914) el relato "Las botas de cien lenguas” y también lo acompaña de tres ilustraciones (imagen 5), una de ellas ofrece un contenido adicional al de la historia. Las dos primeras se refieren de modo más directo al texto escrito. En una se contempla la escena de unos niños: "Una vez vio a otros chicuelos de su edad, que con una piedra hacían pedazos una lagartija, y, al observar que cada trozo se movía por separado, quedó absorto...” (s.a. 1914: 262); la ilustración exhibe este momento y da cuenta de cierta deformidad en sus rostros, lo cual acentúa el carácter de malicia que se narra. El centro del grabado lo ocupa 
el niño con la piedra, quien está ubicado en un plano más cercano que el resto; de esta manera, se subraya el acto del niño, se llama la atención en la ilustración de la misma forma en que fue objeto de atención para el joven que fue testigo de la escena. Así, este cuadro se estructura como aquel que vio el personaje; se completa la información del texto con estos elementos visuales: el espacio, los cuatro “chicuelos", la lagartija despedazada, la gran piedra y las caras de maldad. En la siguiente ilustración se aprecia al personaje frente a otro, se advierte una jerarquía que se refuerza en la diferencia de tamaño, de luz y disposición de ambas figuras. Más aún, el joven mira al adulto hacia arriba y se establece una relación vertical entre ellos. El adulto tiene unas grandes manos y sostiene un libro con unas dimensiones inusitadas. A diferencia del niño, él no lo mira, la vista se dirige al horizonte. Este personaje sobresale en la imagen. La historia enuncia: "En esto apareció a su lado una matrona de bastante edad, de cabellos blancos y severo aspecto" (s.a. 1914: 262) y luego le dice: "Soy la ciencia-exclamó la matrona” (s.a. 1914: 262). Resulta sugestiva la forma en que el ilustrador configura la apariencia de la Ciencia y le otorga un poder frente al espacio y al niño que está a su alrededor.

Aquí, como en la anterior ilustración, se brinda información adicional que aporta y resalta el contenido declarado en el texto escrito. El último grabado es el más interesante puesto que es una construcción libre del grabador, no se enlaza con un fragmento en particular. Esta imagen puede ser interpretada a partir de la revelación que le realiza la Ciencia, la matrona, después de que el joven recorre el mundo con las botas de siete leguas en busca del "secreto de la vida": "Voy a decirte quién tiene el secreto de lo que buscas. Y levantando el brazo señaló con el dedo la inmensa bóveda del firmamento. -Sólo Dios, exclamó, posee la clave de ese misterio y no es dado al hombre levantar ni una punta del velo que lo cubre, a no ser por expresa revelación del mismo Dios” (s.a. 1914: 263). El árbol con frutos, en el dibujo, simboliza ese conocimiento develado; el hecho de que los misterios son inalcanzables e inaccesibles al hombre. Incluso, la Ciencia, después de entregarle las botas, le promete al joven que se verán luego en su palacio, que es la montaña de la Experiencia "levantada con las cenizas de los sabios, apisonada por sus vigilias y sus esfuerzos” (s.a. 1914: 262); así, llegar adonde la Ciencia, a su palacio y recibir sus consejos significa poder tomar sus frutos. Esta ilustración cuenta con una carga simbólica y una función creadora del grabador de gran relevancia para este análisis, en la medida en que muestra un modo diferente de relación entre imagen y texto que los independiza, aunque sin separarlos.

Esta serie de tres imágenes resalta tres perspectivas precisas del cuento; en primer lugar, la existencia de los actos de maldad y la profanación del derecho a la vida; la preponderancia que tiene la ciencia, el respeto y el poder del que goza, y el acceso a los conocimientos de la ciencia y el saber en conexión con la misma imposibilidad del hombre de descubrirlo y conocerlo todo. Las ilustraciones amplían el contenido del relato y colaboran en el refuerzo de algunos temas centrales. En comparación con la secuencia de "A flor de tierra", estas tres imágenes estructuran un relato, si bien ligado al texto escrito, paralelo a este, se marca de manera más contundente el hilo de los hechos, ya que el grabado del personaje femenino en la publicación de Lectura y arte no logra ser fuertemente esclarecedor para dar cuenta de lo que aconteció entre la imagen del enfermo y del 
hombre muerto, mientras que en la historia de La Niñez se consigue una configuración más patente, a pesar, incluso, de la ilustración de corte simbólico.

Ahora, es necesario traer a colación el cuento "La derrota de Geniolandia” de Carlos Mata, publicado en Rin-rin, no 5 (1936), como ejemplo de la particularidad de las ilustraciones que incluyó esta revista y de una forma especial de esta conexión entre serie de imágenes y texto. Este objeto está compuesto por diez ilustraciones (imagen 6), no son grabados, sino dibujos, muy cercanos a la caricatura. Son expresivos, presentan varias exageraciones en los gestos del rostro, las manos, el cuerpo. Se incluyen dos tintas: negra y violeta, pero se utiliza también el color blanco del papel. Algunas de las imágenes guardan una relación cercana con el texto, como las $d, e, i \mathrm{y} j$; por ejemplo, el cuarto y quinto dibujo constituyen realmente una misma ilustración, pues el hombre anciano, al hacer su alocución, es atendido y observado por un público; en este caso, las palabras que separan ambas imágenes actúan como indicadores de la distancia que media entre ambos personajes y enfatizan en la jerarquía planteada por ellas. Esta jerarquía se comprende a partir de la distinción de las miradas, el hombre ubicado en el lugar superior mira hacia abajo y los personajes de la parte inferior tienen la mirada hacia arriba. Sobresale también la corona sobre el hombre que pide silencio y espera con su gesto. Menciona el cuento:

Iluminándose de pronto el balcón real y ante la muchedumbre apareció el gran Merlín, grave y majestuoso, como en los días de fiesta, y con voz solemne habló así [...] durante unos cuantos minutos fue imposible entender nada hasta que al fin, el duendecillo Pelosrojos, encaramándose sobre los hombros de un fornido genio, levantó la chillona voz y dijo...” (Mata 1936: 7).

La ilustración se detiene en presentar este último momento en el que en medio de la algarabía se alza el duendecillo. La historia se desarrolla en el reino de Geniolandia, donde viven hadas, genios, duendes, brujas y demás "seres maravillosos de los cuentos"; por ello, el ilustrador Sergio Trujillo inserta esa variedad de personajes con fisonomías diversas y extrañas, Trujillo destaca un rasgo por encima de otros: el tamaño de las cabezas, las cuales sobresalen, además, por carecer de pelo; tal característica afirma la condición de "genios" por asociación metonímica entre la genialidad y la cabeza; más aún la cabeza grande. Trujillo, por tanto, complementa lo referido en el texto escrito con detalles de los personajes y resalta la relación jerárquica entre Merlín y sus súbditos.

El dibujo $j$ evidencia el momento en que un tren es confundido con un dragón y por eso es atacado, el enlace texto-imagen es muy cercano, ambos elementos ofrecen los mismos datos, aunque con las distinciones propias de sus medios de expresión verbal-visual. Asimismo, en el $i$ se exhibe una descripción enunciada en la historia, con la disimilitud de que esta vez con la imagen se refuerza el tono cómico del texto respecto a la cantidad de condecoraciones del personaje para dar cuenta de su sapiencia. La ilustración acompaña la hipérbole expuesta en el cuento.

Por el contrario, las imágenes $a$ y $c$ refieren una conexión más distante del cuento, pues se estructura una escena particularizando la información que se aprecia en el texto escrito de forma más general. En primer lugar, se ven tres figuras con fisonomías distintas paradas una al lado de la otra en medio de la 


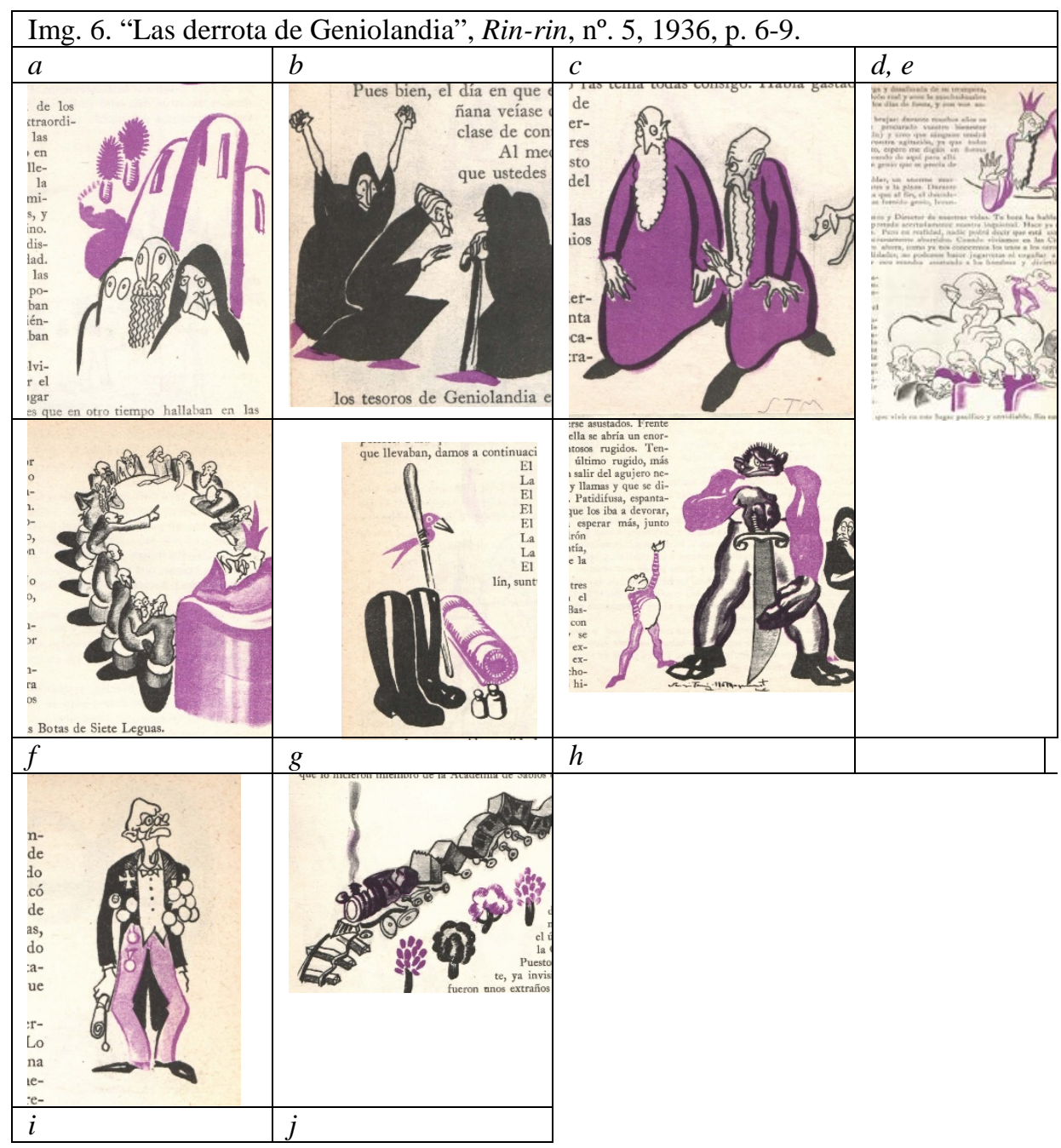

ciudad; este dibujo se ubica al lado derecho del párrafo que narra el inicio de la historia, aunque no se enuncia con exactitud ese instante, se comprende que es una manera de presentar gráficamente a los habitantes de Geniolandia. De igual modo, en la ilustración $c$ se observa a dos hombres caminando y hablando y detrás de ellos hay un perro escuálido. Esta escena no se conecta con un fragmento explícito del cuento de manera directa, tan solo se vincula con la situación de murmuraciones, aunque los personajes más que murmurando, están conversando. La inclusión del perro es un elemento extraño y difícilmente explicable dentro de la narración; es complejo definir si se incluye como elemento adicional de la ilustración, del cuento o de ambos (dada la intrínseca relación que establecen).

Las imágenes $b$, f y $h$ se vinculan de forma clara con el cuento, aunque no de un modo tan directo como las ilustraciones $d, e, i \mathrm{y} j$, y tampoco tiene la distancia de las mencionadas en los párrafos anteriores. Los dibujos aportan información más 
específica a los hechos o descripciones escritas. En la ilustración $b$ se enseñan los personajes que participaron de las murmuraciones: "Desde la mañana veíase correr a los genios, grandes y chicos, de aquí para allá, murmurando y haciendo toda clase de contorsiones y visajes. Lo mismo pasaba con las hadas, las brujas y los duendes.” (Mata 1936: 6). Se precisa un ejemplo puntual de este hecho en las tres figuras que cuchichean de forma misteriosa.

Igualmente, el dibujo $f$ exhibe una discusión entre Merlín y varios personajes, se especifican los participantes y las circunstancias de aquello que el cuento describe: "Durante 17 días con sus noches, los habitantes de Geniolandia discutieron la proposición de su soberano" (Mata 1936: 7). Trujillo expone una especie de selecto grupo que deliberó con el rey Merlín. Esta imagen es una construcción, de cierto modo, independiente del ilustrador, pues presenta con autonomía aquellos "habitantes".

A su vez, las figuras exhibidas en $h$ dan cuenta del grupo de elegidos para visitar las ciudades de los seres humanos, a manera de liga de superhéroes de tira cómica; en el texto estos seres se describen por separado, luego se alude que todos se congregaron para verlos partir. Esta imagen complementa este momento del cuento, se configura cómo se veían los personajes: la bruja Patidifusa, el genio Tolondrón y Pelosrojos, el duende.

Sergio Trujillo muestra con estas ilustraciones, como se pudo advertir, tres formas particulares de conectarse con el texto (si se toman cada una por separado, no como parte de una serie): una relación estrecha con el cuento, otra en la cual aporta y completa con otros detalles lo que se menciona en la historia, y una que crea mayor distancia, por lo cual se hace complejo distinguir el fragmento al cual alude.

La secuencia creada por estas imágenes, a pesar de las diez ilustraciones que incluye, no posibilita hacer una lectura de la historia a partir únicamente de ellas, ya que el final no es ilustrado. No obstante, por lo menos hasta una buena parte del cuento, es posible seguir el relato a través del vínculo entre imagen y texto. La diferencia con las demás series citadas, aparte de la cantidad, se contempla gracias a la expresividad del dibujo, a los rasgos caricaturescos que dotan de una especificidad y autonomía a la ilustración frente al cuento. Se percibe en esta secuencia una participación particular del dibujante.

La principal similitud entre las series es que configuran una lectura alterna de la historia a través de las escenas que escogieron los ilustradores; así, el cuento utiliza otra manera de narrar la historia, una visual, que la dota de un contenido adicional y complementario que estructura un producto creado por ambos elementos, motivo por el cual este producto no es posible ya dividirlo, se compone tanto de la imagen como del texto.

\section{Cuento mudo}

En La Niñez se incorporan algunos ejemplos de este tipo de publicación. Constituye una serie de imágenes que se disponen en orden numérico y carecen de texto. En el ejemplo citado (imagen 7) titulado en la revista como "Cuento mudo" (1914), se aprecia la narración de cómo un hombre afrodescendiente encierra a un 
caimán o cocodrilo en un tronco. Se va mostrando poco a poco el movimiento del hombre y la reacción del animal. Es un dibujo sencillo, con líneas simples que plantea un marco de referencia que define el contexto espaciotemporal de las escenas; sobre este se ubican las figuras que son protagonistas de la historia. La dimensión temporal se indica por la sucesión de imágenes y los cambios de la disposición de los personajes.

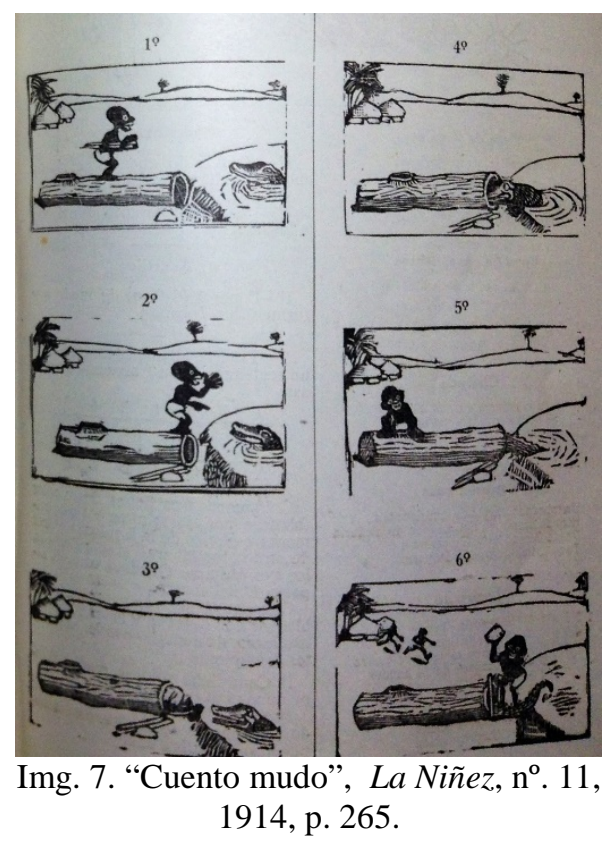

Resulta interesante que se incluyan estos relatos narrados solo con imágenes pues evidencia una actividad de lectura distinta, donde ya no es la imagen la que sigue el texto, sino que esta misma narra la historia. Es importante resaltar el hecho de que se indique con números el orden en que debe leerse, ya que atiende a una necesidad o a una dificultad que puede surgir en la lectura, la cual no se plantea de forma horizontal (de izquierda a derecha) como se lee un texto escrito, sino que se organiza verticalmente, dando inicio por la columna izquierda. La narración tiene un elemento de comicidad y de entretenimiento frente a otros productos de las revistas estudiadas que guardan propósitos moralizantes. En este caso, la comicidad se afinca en la malicia del hombre frente a la ingenuidad del animal.

\section{Historias historiadas}

Por último, se introduce un objeto que se compone de historias contadas mediante historietas. En estas, la imagen tiene una preponderancia mayor al texto escrito, que se supedita a ella para ampliar con descripciones verbales, insertar diálogos o acentuar un contenido. Por ejemplo, en la historieta (imagen. 8) publicada en el $n^{\circ}$. 
14 (1914), se aportan los nombres de los personajes para reconocerlos y se ofrecen detalles para evitar confusiones, como "el otro perro"; sin embargo, lo más notable es la inserción de expresiones como "por pura maldad" y la moraleja, puesto que contribuye a dotar de un significado moral preciso a la historia presentada en las imágenes. Hay un acompañamiento a la lectura de la imagen guiado por frases dispuestas, se enumera la secuencia para ayudar en el seguimiento del relato.

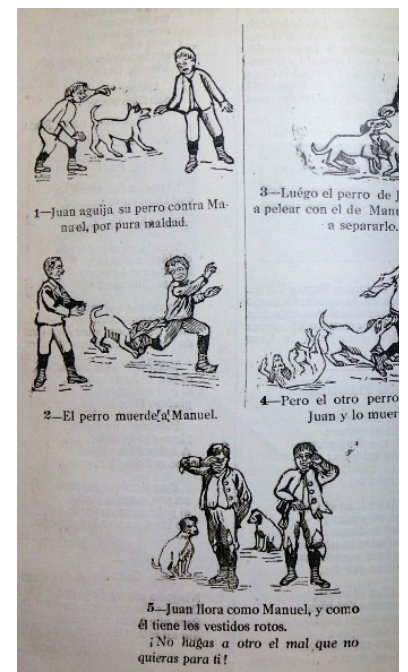

Img. 8. La Niñez, $\mathrm{n}^{0}$. 14, 1914, p. 212.

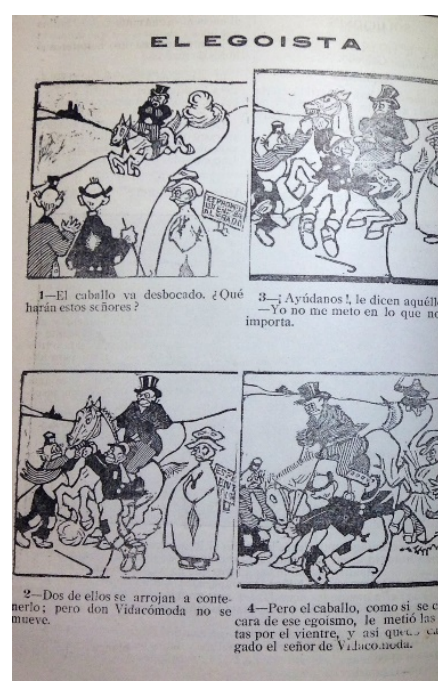

Img. 9. “El egoísta”, La Niñez, $\mathrm{n}^{\circ} .17,1914$, p. 262.

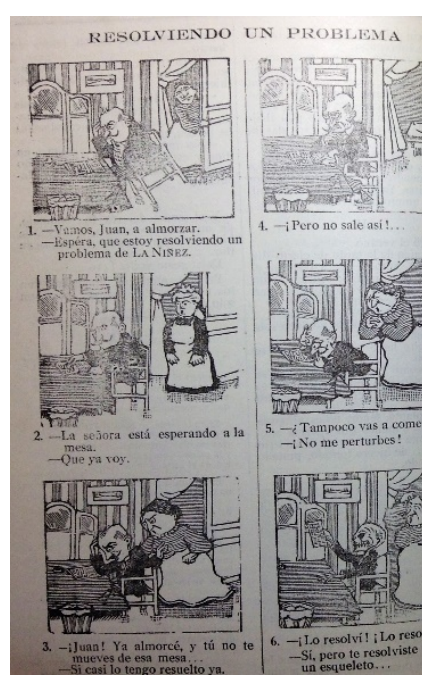

Img. 10. "Resolviendo un problema”, La Niñez, $\mathrm{n}^{\circ}$. 26, 1914, p. 406.

En "El egoísta” (imagen 9), incluida en el nº 17 (1914), se añade una pregunta al lector: “¿Qué harán estos señores?”, asunto que evidencia la existencia de un lector ideal, -consumidor- estructurado por el productor, el escritor del texto, quien lo involucra en la historia. En esta ocasión, a parte de las expresiones que se refieren de forma directa a la imagen, también se introducen expresiones de orden moral como "pero don Vidacómoda no se mueve", "como si chocara de ese egoísmo” y "así quedó castigado el señor don Vidacómoda” que robustecen el contenido que las imágenes disponen con las tensiones entre los protagonistas y las acciones allí presentadas, la oposición entre los personajes que se prestan a ayudar y quien se abstiene de hacerlo, la patada del caballo hacia "don Vidacómoda” y los gestos que evidencian las facciones de los hombres.

Por otra parte, sobresale la inclusión de diálogos en esta historieta, y en otras como "Resolviendo un problema" (imagen 10) publicada en el $n^{\circ} .26$ (1914), aunque no se insertan con globos, sino que se ubican, asimismo, en la parte inferior como en los demás casos. En "Resolviendo un problema", el contenido no es de carácter moral como en otros productos, sino cómico; mediante una hipérbole revela la dificultad de los acertijos que publica la revista regularmente. De acuerdo con el análisis, estos son los aspectos centrales del contenido de las historietas 
incluida en La Niñez: el carácter moralizante o cómico, incluso una combinación de los dos.

\section{A modo de conclusión}

Este artículo se propuso analizar los textos narrativos ilustrados (visuales o verbales) publicados en las revistas Lectura y arte, La Niñez y Rin-rin, centrándose principalmente en los productos literarios, es decir, los textos; sin desconocer el lugar que ocupan en el sistema literario y, por tanto, las relaciones que trazan con los demás elementos. En algunos casos, por ejemplo, se aprecia la figura de un productor que crea el texto y la imagen, como la colaboración infantil publicada en Rin-rin o, aunque no se precisa, en las historietas de La Niñez; en otros se contemplan dos productores, el escritor y el ilustrador, que crean dos objetos que logran considerar una unidad, e incluso un productor que se comprende únicamente en su función artística, visual, en el "cuento mudo".

El presente trabajo esboza una relación especial del género narrativo, en particular del cuento frente a la ilustración, su dimensión temporal parece ser un elemento clave en la incorporación de imágenes que se conectan con el texto escrito. No obstante, esta es una cuestión que requiere de una investigación más detallada y pormenorizada, puesto que es necesario observar y distinguir las conexiones de imágenes con textos de otros géneros literarios, narrativos, poéticos o dramáticos, por ejemplo. Valga la pena traer a colación las ilustraciones de Salomé de Oscar Wilde por Aubrey Beardsle o de Gustave Doré en El Ingenioso Hidalgo Don Quijote de la Mancha. ¿Se presentan distinciones frente a las relaciones que las imágenes tienen con los textos diferentes al cuento?

Ahora, definir el repertorio en estos objetos requiere de la reflexión acerca de lo que se entiende como cuento y en particular como "cuento ilustrado". Gracias a las categorías halladas en el estudio de los productos, se encontraron cuatro manifestaciones de lo que se define como cuento ilustrado, por lo menos en las revisadas usadas como fuente. Primero, se entiende como una narración verbal que se relaciona con una imagen que expresa una o varias escenas o elementos de la historia. También se comprende como aquel relato verbal que se acompaña por una serie de ilustraciones que estructuran el contenido de la historia enfatizando en ciertos aspectos, dentro de las imágenes se encuentran algunas que se conectan de manera más directa que otras con el texto escrito. Luego, cuento ilustrado se define asimismo como la "narración" muda, es decir, el relato construido con imágenes y ordenado en una secuencia. Finalmente, se concibe, de igual modo, a manera de historieta cómica. De esta manera, es preciso recurrir, por lo menos, a dos características fundamentales en la definición de la noción de "cuento ilustrado", una es el aspecto visual, artístico, gráfico: la imagen; otra, la dimensión narrativa del texto; es importante, entonces, en este punto reconocer la narratividad de una imagen.

En otro sentido, ¿qué puede afirmarse acerca del consumidor de estos productos literarios? La Niñez y Rin-rin son revistas cuyo público lector ha sido concebido por la misma publicación como el infantil, pero no exclusivamente, ya que su carácter pedagógico también posibilita declarar que los adultos, maestros y padres 
primordialmente, hacen parte del público objetivo. Frente a lo que se exige o se requiere del lector, se observa que, aparte de leer textos escritos, se busca fomentar la lectura de imágenes. Es interesante la manera en que se enumera el cuento mundo y la historieta, pues estructura una guía en que debe leerse la secuencia. De igual forma, la lectura compartida de ambos textos ayuda, en algunos casos, a verificar la comprensión del escrito en la medida en que guardan una relación.

El consumidor pensado por las revistas, sin mencionar la edad, debe realizar una lectura doble, de dos objetos y de dos formas distintas, además se abre la posibilidad de que el lector confronte su lectura con aquello que realizó el ilustrador y que se incluye en la publicación en compañía del texto escrito como una unidad comprensiva de dos elementos.

En este sentido, la prensa ilustrada, a diferencia de las demás publicaciones periódicas, propone una relación bastante particular, específica, entre dos formas de leer; relación que es necesario profundizar, de modo que se logre reflexionar con más detalle cómo la simultaneidad de ambos códigos logra afectar al público lector. El lector puede leer ambos, uno u otro, complementarlos o separarlos, discutir con ambos; esta lectura bifocal transforma, en cualquier caso, la comprensión. ¿Cómo modifica esta condición la manera de leer de la actualidad? ¿Cómo conectarlo con las novelas ilustradas, los cómics, los libros-álbum? Por otra parte, se encuentra otra perspectiva de análisis que se desprende de los productos analizados, la constituye los textos ilustrados infantiles. En este caso, la función de las imágenes tal vez pueda verse influenciada por los factores de formación lectora y de aseguramiento de la comprensión. Sería interesante ahondar más en este asunto para hallar las diferencias con obras literarias ilustradas que no se consideran infantiles como Don Quijote de la Mancha, la Divina Comedia, el Decamerón, entre muchas otras que actualmente se han editado en versiones bellamente ilustradas.

Finalmente, es relevante mencionar que dentro del corpus se hallan las revistas Michín (1938-1948), Chanchito (1933-1934) y Cromos (1916-1934), que pueden complementar el análisis aquí propuesto pues dentro de sus números incluyen un número considerable de imágenes que ayudarían a ampliar la reflexión esbozada en el presente trabajo.

\section{Referencias bibliográficas}

\section{Fuentes primarias}

Mata, Carlos, “La derrota de Geniolandia”, Rin-rin, n. 5, mayo de 1936, pp. 6-9.

Molana, Álvaro, “Una batalla china”, Rin-rin, n. 3, marzo de 1936, p. 15

Pombo, Rafael, “La pobre viejecita”, Rin-rin, nº 6, junio de 1936, pp. 10-11.

Restrepo, Carlos E., “Risa trágica”, Lectura y arte, no. 11, julio de 1905, pp. 202-203

Restrepo, Saturnino, “A flor de tierra”, Lectura y arte, $n^{\circ} .7$ y 8, noviembre de 1905, pp. 129-141

S.A., “El egoísta”, La niñez, nº 17, junio 13 de 1914, pp. 262.

—“Cuento mudo”, La niñez, no. 11, abril 25 de 1914, pp. 265.

—_Las botas de cien leguas”, La niñez, no. 11, abril 25 de 1914, pp. 262-264.

—_Resolviendo un problema”, La niñez, no. 26, agosto 15 de 1914, p. 406. 
—_Sin título”, La niñez, nº. 14, mayo 25 de 1914, p. 212.

\section{Obras citadas}

Even-Zohar, Itamar. El sistema literario. Disponible en línea: http://www.tau.ac.il/ itamarez/works/papers/trabajos/EZ-sistema_literario.pdf

Furió, Vicenç. Ideas y formas en la representación pictórica. Barcelona: Universitat de Barcelona, 2002.

García Varas, Ana, “Lógicas de la imagen”, en Ana García Varas (ed.). Filosofía de la imagen. Salamanca: Ediciones Universidad de Salamanca, 2011, pp. 15-56.

Gil-Díez Undizaga, Ignacio, "Bretón y la imagen costumbrista”, en Miguel Ángel Munro. La obra de Manuel Bretón de los Herreros II Jornadas bretonianas. Logroño: Instituto de Estudios Riojanos, 2000, pp. 33-56

Giraldo, Gabriel. La miniatura, la pintura y el grabado en Colombia. Bogotá: Instituto Colombiano de Cultura, 1980.

Kibédi Varga, Áron, “Criterios para describir las relaciones entre palabra e imagen”, en Antonio Monegal (comp.). Literatura y pintura. Madrid: Arco Libros, 2000, pp. 161183.

Reyes, Carlos José, “El costumbrismo en Colombia”, en Manual de literatura colombiana. Bogotá: Procultura, 1988, pp. 175-245.

Rifaterre, Michael, "La ilusión de Ecfrasis”, en Antonio Monegal (comp.). Literatura y pintura. Madrid: Arco Libros, 2000, pp. 161-183

Rodríguez Gutiérrez, Borja. El Artista en El Laberinto: un recorrido por la prensa romántica ilustrada. Santander: Tremontorio, 2011.

Tatarkiewicz, Wladislaw. Historia de seis ideas. Arte, belleza, forma, creatividad, mímesis, experiencia estética. Madrid: Editorial Tecnos, 2010. 